\title{
FORMAÇÃO PROFISSIONAL: AS VIVÊNCIAS DOS JOVENS EM UM PROGRAMA DE APRENDIZAGEM
}

\author{
Manuella Castelo Branco Pessoa \\ Universidade Federal da Paraíba \\ Maria de Fátima Pereira Alberto \\ Universidade Federal da Paraíba
}

\begin{abstract}
Resumo
Este artigo objetiva analisar as vivências de um grupo de jovens participantes de uma experiência de formação profissional no Programa Jovem Aprendiz (PJA). Utilizou-se metodologia qualitativa e entrevista semiestruturada, analisada através da análise de conteúdo temática. Participaram 20 jovens com idades entre 15 e 22 anos. Os dados mostram que, apesar de não demandarem a inserção no PJA, os jovens aliaram suas necessidades financeiras e das famílias ao discurso do mercado de que é necessário ter experiência para se conseguir um emprego. As vivências no PJA fizeram com que percebessem que tiveram oportunidade de: ter formação profissional; adquirir experiência; aprender técnicas bancárias; conseguir o primeiro emprego. Interpretam que precisam agarrar essa oportunidade e, diante disso, reagem, com sofrimento, ao peso da responsabilidade de que não podem falhar.

Palavras-chave: formação profissional; política pública; juventude.
\end{abstract}

\section{VOCATIONAL TRAINING: THE EXPERIENCES OF YOUTH IN A LEARNING PROGRAM}

\begin{abstract}
This article aims to analyze the experiences of a group of young participants in a vocational training experience in Young Apprentice Program ( $P J A$, in Portuguese). It was used qualitative methodology and semi-structured interviews, analyzed through thematic content analysis. Participated 20 young people aged between 15 and 22 years. The data shows that despite not they demand insertion in PJA, the young people allied financial needs of families and the speech that it is needed experience to get employed. With the experiences in PJA, they realized that they had an opportunity to: get a professional initiation, gain experience, learn banking techniques, find the first job. Thus, they interpret that they need to take this opportunity, what makes them feel the weight of responsibility that cannot fail, which causes suffering.

Keywords: vocational training; public policy; youth.
\end{abstract}




\title{
FORMACIÓN PROFESIONAL: LA EXPERIENCIA DE LA JUVENTUD EM UM PROGRAMA DE APRENDIZAJE
}

\begin{abstract}
Resumen
Este artículo tiene como objetivo analizar las vivencias de un grupo de jóvenes, participantes del Programa Joven Aprendiz (PJA). Fue utilizada la metodología cualitativa y una entrevista semi-estructurada, analizada mediante Análisis de Contenido Temático. Participaron 20 jóvenes de entre 15 y 22 años. Los datos muestran que a pesar de no querer la inserción en el PJA, los jóvenes unieron sus necesidades financieras y la de las familias al discurso que se necesita experiencia para conseguir ingresar en el mercado de trabajo. Con las experiencias en el PJA, ellos se dieron cuenta de que tenían una oportunidad para: tener una formación y experiencia, aprender técnicas bancarias y obtener el primer empleo. Así, interpretan que necesitan aprovechar esta oportunidad y por eso sienten el peso de la responsabilidad que no se puede fallar, lo que los provoca sufrimiento.
\end{abstract}

Palabras clave: formación profesional; políticas públicas; jóvenes.

\section{INTRODUÇÃO}

O presente artigo tem como objetivo analisar as vivências em uma experiência de formação profissional por parte de um grupo de jovens participantes do Programa Jovem Aprendiz (PJA). Esse programa compõe uma das políticas públicas para a juventude, executadas na atualidade por parte do Estado brasileiro envolvendo instituições privadas: empregadoras e formadoras.

O Programa Jovem Aprendiz (PJA), cujo objetivo é a formação técnicoprofissional, foi regulamentado através da Lei 10.097, de 19 de dezembro de 2000, alterada pelo Decreto no 5.598, de $1^{0}$ de dezembro 2005, que modificou a idade para a inserção no programa, ou seja, dos 14 aos 24 anos. Também determina que todas as funções de uma empresa com, pelo menos, sete empregados que demandem formação profissional devem ser consideradas para efeito do cálculo da cota de aprendiz, salvo funções que requerem formação superior ou técnica, que é fixada entre $5 \%$ e $15 \%$.

O PJA operacionaliza-se através de um contrato de trabalho, regularizado por escrito e com prazo determinado, tendo duração máxima de dois anos, com todas as garantias trabalhistas. Nele, a empresa empregadora se compromete a garantir ao adolescente e ao jovem uma formação técnico-profissional metódica (Ministério do Trabalho e Emprego, 2006), que são atividades teóricas e práticas, metodicamente organizadas em tarefas de complexidade progressiva desenvolvidas no ambiente de trabalho. Tais atividades acontecem sob a responsabilidade de uma instituição com fé de ofício para tal. O jovem, por sua parte, compromete-se a cursar a parte teórica na instituição responsável pela formação técnica e realizar a parte prática na empresa.

Dentre os direitos dos aprendizes estão: salário mínimo, levando em consideração que a falta ao curso pode ser descontada no salário, com jornada de trabalho de 6h/diárias para os que ainda não concluíram o Ensino Fundamental, e no máximo 8 h/diárias para os que já concluíram. Para os que possuem menos de 18 anos é proibido o trabalho noturno, que tenham 
atividades perigosas, insalubres ou penosas, ou realizadas em locais que prejudiquem seu desenvolvimento psíquico, físico ou moral; o aprendiz também tem direito a vale transporte, e suas férias devem coincidir com as férias escolares. É de responsabilidade da empresa designar monitores responsáveis para acompanhar e coordenar o aprendiz no exercício das atividades práticas no estabelecimento.

As instituições formadoras compreendem principalmente o Sistema S Serviço Nacional de Aprendizagem Industrial (Senai), Serviço Nacional de Aprendizagem Comercial (Senac), Serviço Nacional de Aprendizagem do Transporte (Senat) e Serviço Nacional de Aprendizagem Rural (Senar) - ou, na impossibilidade desse sistema, uma instituição privada filantrópica ou organização não governamental autorizada por uma Superintendência Regional do Trabalho.

Embora as ações para formação profissional de jovens no Brasil datem de 1940, com a criação do Sistema S, somente com a Constituição Federal de 1988 pode-se falar em políticas públicas entendidas como direito de cidadania, obrigação do Estado e como um conjunto de ações e decisões em forma de resolução para os problemas sociais (Sposito \& Carrano, 2003). Essas ações encontram na sociedade brasileira um respaldo na qual a educação e a formação profissional ganham lugar central nessas políticas públicas para juventude, às quais são conferidas funções essencialmente instrumentais, que possibilitam a competitividade, intensificam a concorrência, adaptam os trabalhadores às mudanças tecnológicas além de minimizar os efeitos do desemprego (Segnini, 2000).

Frigotto (2008) analisa essa perspectiva da relação entre formação e trabalho por outra via. Para ele, a reforma da educação profissional ajusta-se às relações de produção capitalista, a formação é adestrada para o capital. Assim, a educação profissional tem sido planejada para a simples aquisição das competências que se enquadrem na lógica do empregado produtivo, adaptável, que produza em tempo mínimo, e cuja mercadoria tenha aceitação imediata. De modo que a educação profissional é feita com características mais tecnicistas, conteúdo aligeirado e restrito a técnica, sem considerar a formação integral do trabalhador e sem atentar para as suas necessidades e nem para as questões sociais.

A questão social é aqui entendida como o conjunto dos problemas políticos, sociais e econômicos expressos por meio da contradição capitaltrabalho das exigências do processo de construção da sociedade capitalista. A questão social conduziu no processo histórico da luta de classes - entre os trabalhadores e os donos dos meios de produção- a institucionalização de direitos sociais. Os quais se materializaram através de políticas de proteção social ou políticas sociais. Uma das formas que as políticas de proteção social tomaram se consolidou através do conceito de políticas públicas para tratar da 
área de proteção social definida ou concebida como direito do cidadão e obrigatoriedade do Estado. (Yamamoto \& Oliveira, 2010).

Nos últimos anos percebe-se um crescimento de estudos na área de políticas públicas voltadas para esse segmento, com destaque para a formação para o mercado de trabalho, que tem sido objeto de investigação de autores como: Souza (2009), Pochmann (2000); Thomé, Telmo e Koller (2010), que analisam a formação profissional e a inserção de jovens no mundo do trabalho. Assim como Soares (2009), que faz a discussão do trabalho como uma forma de disciplinamento dos jovens, Sposito e Corrochano (2005) destacam a configuração do trabalho como via inevitável para jovens das classes baixas.

Souza (2009) observa que as políticas públicas de qualificação profissional para o segmento jovem estão inseridas no conjunto de políticas de "conformação subalternas", apenas com o objetivo de mediar os conflitos e de manter a hegemonia do projeto neoliberal (p. 4), forma na qual o Estado procura reduzir ainda mais os gastos com a proteção social do trabalhador. Também Thomé, Telmo e Koller (2010), constataram que a inserção dos jovens no mundo do trabalho ocorre de forma precária, muitas vezes pela via informal, sem direitos ou garantias trabalhistas assegurados, o que gera sofrimento para os jovens. Devido a mudanças estruturais e culturais, a participação no mercado de trabalho é vista como uma condição para a realização plena do indivíduo (Rocha, 2008).

Há estudos específicos também em relação ao PJA como os de: Macêdo e Alberto (2012) e Silva (2006), no PJA, realizado pelo SENAC; Santos (2006), na experiência do SENAI; por Dias (2006), no Programa desenvolvido por uma Organização Não Governamental (ONG); Máximo (2012), no PJA no SENAC, SENAI, no Centro de Integração Empresa-Escola (CIEE) e ONGs; Amazarray, Thomé, Souza, Poletto e Koller (2009), no PJA no Rio Grande do Sul, discutindo a formação e futuro profissional.

Santos (2006), ao investigar a percepção dos aprendizes sobre o programa do SENAI, identificou que a experiência, bem como a carteira assinada, aparecem como a maior contribuição do programa para a inserção no mercado. Na visão desses jovens, o SENAI surge como um relevante referencial de formação que serviria como um símbolo de que o jovem que lá realizou qualificação está apto a preencher uma ocupação no mercado. Macêdo e Alberto (2012), ao estudar o sentido da formação para o trabalho por parte de aprendizes do SENAC, identificou que no SENAC não há uma formação humanista, mas uma formação utilitária para o mercado, que se propõe a formar indivíduos compatíveis com essas demandas. Dessa forma, através dos instrumentos disciplinares, procede para transformar "massa inútil em algo útil", através da homogeneização dos jovens.

Máximo e Alberto (2012), ao analisar o significado da formação e inserção no mercado de trabalho para aprendizes egressos e gestores do PJA, na cidade 
de João Pessoa- PB, constatou que a maioria dos aprendizes ainda é inserida por ação fiscal, o que significa que as empresas só recebem os jovens mediante a exigência do órgão fiscalizador. Ela identifica que a maioria das empresas só aderiu ao programa em decorrência da fiscalização e que os mesmos fazem críticas aos cursos por causa do custo, da superficialidade dos conteúdos ministrados e da falta de uma relação mais sistemática entre empresa e instituições formadoras. Segundo os jovens, a participação no programa se constitui como um diferencial no processo seletivo para inserção no mercado de trabalho. Nesse aspecto eles não se referem à formação, mas sim à prática na empresa. O significado do trabalhar emerge como um antídoto aos riscos da juventude e a inserção no mercado de trabalho, apresentada como a salvação daquele jovem.

A literatura acima citada possibilitou compreender: como o PJA se propõe enquanto uma política de formação profissional; a forma como os atores sociais que dela participam percebem o referido programa; e o sentido do trabalho e da inserção profissional. Na pesquisa que originou este artigo abordaram-se as vivências desses jovens, ou seja, como eles experienciam essa inserção em uma política social. Estudar vivências possibilita analisar as dimensões cognitivas e afetivas e, além disso, a constituição desse sujeito. Para tal, utilizou-se como ferramenta teórica o conceito de vivência na perspectiva vigotskiana, compreendida como uma relação interior do ser humano com um momento da realidade, intermediada entre a personalidade e o meio (Vigotski, 19331934/2006).

Toassa (2009) afirma que o conceito de vivência atravessa toda a obra de Vigotski, desde suas primeiras produções até as últimas. Desse modo, "as vivências inscrevem-se numa temporalidade de fatos que se estendem no passado, presente e futuro da vida psicológica" (Toassa, 2009, p. 28). É um tipo de apreensão do real que integra o emocional e o cognitivo, o que significa que, em uma situação, diferentes características podem ser implicadas. Para isso, deve-se levar em consideração o nível de desenvolvimento e a consciência somando-se aos recursos que tem para compreender, o interno e o externo (Toassa \& Souza, 2010).

Segundo Vigotski (1933-1934/2006), a vivência é uma unidade dinâmica da consciência, cuja base abrange a forma como se percebe, se interpreta um evento e se reage emocionalmente a ele. Ela também comporta características da consciência, fazendo uma inter-relação entre os aspectos cognitivos e afetivos, influenciando o desenvolvimento em seus diversos aspectos. Nem todas as características pessoais estão envolvidas de uma vez; assim, apenas algumas terão papel decisivo dependendo da situação experimentada. Para o autor, é importante conhecer quais características têm papel central em determinadas situações, levando em conta o nível de desenvolvimento, a consciência, os 
recursos pessoais, visto que os eventos podem ter impactos diferentes, a depender do ponto de desenvolvimento.

Vygotsky (1989) trata o desenvolvimento como processo dialético no qual o ser humano se transforma inserido em uma relação complexa entre fatores internos e externos. Diz respeito ao "surgimento de formações qualitativamente novas, com ritmo próprio e que precisam sempre de mediações especiais" (Teixeira, 2003, p. 243). Uma formação nova contempla uma estrutura da personalidade, composta por novas atividades e transformações psíquicas e sociais que, por sua vez, determinam a consciência e a forma da relação com o meio (Vigotski, 2006). A análise do desenvolvimento deve levar em consideração a ligação do período com o tipo de atividade que o caracteriza, "na qual os processos psíquicos particulares tomam forma ou são reorganizados e da qual dependem, de forma mais íntima" (Teixeira, 2003, p. 240). No caso da juventude, segundo Teixeira (2003), a atividade é constituída pelo período da comunicação íntima pessoal, seguida pela atividade profissional e de estudo.

Assim, a vivência é a unidade da vida que congrega referências do mundo externo e interno (corpo, meio, ideias, representações e funções psíquicas) (Toassa \& Souza, 2010). No grupo de jovens aqui estudados, abordamos a vivência como referência à forma como o sujeito percebe, interpreta um evento e reage emocionalmente a ele mediado pelos significados que lhe são atribuídos pela sociedade, nesse caso, o Programa Jovem Aprendiz (PJA).

\section{MÉTODO}

\section{Participantes}

Participaram da pesquisa 20 jovens, dentre 98 integrantes do Programa Jovem Aprendiz realizado por uma entidade filantrópica específica da cidade de João Pessoa-PB, com idades entre 15 e 22 anos, inseridos nos cursos de Serviços Bancários e Administrativos da Caixa Econômica Federal, Rotinas Administrativas e Práticas Bancárias, ofertados por tal entidade. Levou-se em conta o desejo dos jovens em participar da pesquisa, chegando a esse número a partir da saturação dos dados.

\section{Instrumentos}

O instrumento utilizado com os aprendizes consistiu em uma entrevista semiestruturada, contendo questões abertas e fechadas que versavam sobre dados biossociodemográficos, seleção para o programa, motivação para entrada no programa, direitos dos aprendizes, prática na empresa, relacionamento com os funcionários, relacionamento com os chefes, experiência na formação e aplicabilidade dos cursos à prática. 


\section{Procedimentos}

De posse da autorização da Instituição Filantrópica (que faz a formação) e do parecer da Comissão de Ética, conforme Resolução 196 do Conselho Nacional de Saúde, entrou-se em contato com os aprendizes. O critério utilizado na seleção dos participantes foi o de conveniência, considerando-se a experiência de, pelo menos, seis meses no programa. Optou-se por esse recorte por entender que esses aprendizes teriam mais informações e maior vivência no programa.

\section{Análise dos Dados}

Ao fim da coleta, as entrevistas foram submetidas à análise utilizando-se a Análise de Conteúdo Temática (Bardin, 2007). Iniciou-se pela leitura flutuante de todo o material para a organização do corpus de análise; logo após, procedeu-se à tabulação, codificação e categorização dos dados, ao agrupamento das unidades de registro em núcleos temáticos e, por fim, à análise final com as inferências e interpretações dos aspectos apresentados.

\section{RESULTADOS}

\section{Perfil dos Entrevistados e o processo de seleção}

As idades dos participantes entrevistados variaram de 15 a 22 anos, sendo que a maioria se encontrava com 16 anos de idade, 14 eram do sexo feminino e seis do sexo masculino. Quanto à etnia, 13 aprendizes se identificaram como brancos e sete como afrodescendentes. O nível de escolaridade para 12 deles era Ensino Médio incompleto, quatro tinham o curso superior incompleto, três Ensino Médio completo e um encontrava-se no Ensino Fundamental incompleto. A renda per capita das famílias dos jovens entrevistados variou de 150 a 600 reais mensais.

Segundo os participantes da pesquisa, a seleção para a entrada no PJA se deu através do cadastro realizado por uma instituição de ensino- instituição essa de caráter filantrópico, mantida por empresas privadas- que, por sua vez, têm convênio com a instituição formadora - também filantrópica. A partir do cadastro, foi feita a seleção para o cargo de jovem aprendiz e uma entrevista, esta última realizada na própria empresa empregadora.

\section{Motivação para entrada no Programa}

Diante da forma como foram selecionados, na escola, por terem as melhores notas e não por uma demanda dos aprendizes, a entrevista, segundo momento da seleção, foi um elemento de disciplinamento, momento a partir do qual eles passam a perceber o Programa de Aprendizagem como uma oportunidade para adquirirem experiência profissional, atender à sua 
necessidade financeira assim como da família e também de aprendizagem. Mas foi também um momento de disciplinamento em que as questões e recomendações proferidas ditavam para os aprendizes, nesse momento da etapa de seleção candidatos, como deveriam comportar-se e da responsabilidade deles de dar conta do que dele era esperado, pois essa se constituía numa oportunidade que estava sendo oferecida e que cabia-Ihes aproveitarem.

Os que se referiram à experiência acreditam que o programa poderá oportunizar um futuro emprego, já que a experiência é um aspecto que, segundo os próprios aprendizes relatam, é cobrada e valorizada na hora de ser contratado, o que se coaduna com o que é proposto pelo programa. De certa forma, esse fator também está ligado à renda, não tão diretamente como os que se referiram à necessidade financeira, mas de forma indireta, pois eles acreditam que, com o curso que estão realizando, terão uma oportunidade melhor do que a que seus responsáveis tiveram. Como exemplo temos a fala a seguir: "É importante, pois nos capacita para o mercado de trabalho" (Sexo feminino, 16 anos).

A necessidade financeira está relacionada a pouca renda de que a família dispõe, portanto o salário do aprendiz entra como uma forma de ajuda em casa, como uma forma de contribuir para o aumento da renda familiar e, mesmo que não contribua, só em cuidar de si já é uma ajuda para a família. É dada ênfase também na aprendizagem, pois saber lidar com o cliente, aprender a trabalhar em uma empresa fará o diferencial, para eles, na sua futura inserção no mundo do trabalho.

\section{Direitos dos aprendizes}

Nas falas dos aprendizes, vemos os direitos concebidos em três categorias: uns versaram sobre direitos trabalhistas, outros sobre direitos específicos à lei da aprendizagem e outro, ainda, sobre o direito como dever. Os dados mostram, no primeiro caso, que os participantes demonstram mais um ponto de vista de trabalhador, como, por exemplo, ao citarem férias, $13^{\circ}$ salário, carteira assinada, PIS, salário, FGTS, recolhimento do INSS, auxílio alimentação, vale transporte; o segundo grupo se perceber não como um trabalhador de fato, mas como estudante, voltando-se mais para o funcionamento do programa, quando citam as horas de estudo como direito, as aulas teóricas e a capacitação. No terceiro caso, eles relatam "seguir as regras que foram postas" como um dos fatores mais importantes, ou seja, eles têm que fazer o que os superiores, nesse caso: chefia, funcionários efetivos da empresa, professores, mandarem.

\section{Prática na empresa}

Nas empresas empregadoras, a prática se dá nos serviços administrativos e nos serviços de atendimento. Os aprendizes do setor de serviços 
administrativos desenvolviam atividades como: abertura de conta, informações sobre empréstimo, arquivos, financiamento de imóveis, contratos, auxiliavam no setor fiscal, na gerência, faziam cartões e empréstimos, tiravam xérox, digitavam, desempenhavam serviços de apoio e na retaguarda e ainda faziam o que mandavam ou o que fosse necessário. Enquanto isso, os do setor serviços de atendimento desenvolviam atividades de recepção e encaminhamento do cliente.

A vivência na prática na empresa é, portanto, experimentada pelo contato com o meio bancário, envolvendo as relações com colegas, chefes e público, as quais eles internalizam e reproduzem por uma valoração positiva e negativa. Ao abordarem os aspectos positivos, ressaltam a aquisição da experiência, a aprendizagem na empresa, o lidar com público, a responsabilidade e o contato com um mundo novo. Ainda apontam a prática na empresa como o que mais gostam no programa, pois, para eles, é um momento de aprendizagem, no qual os colegas trabalhadores repassam ensinamentos acerca do serviço. Como exemplo disso, temos a seguinte fala: "Influência que a gente recebe, se espelha nos outros" (Sexo feminino, 17 anos).

Quanto aos aspectos negativos, queixam-se da responsabilização atribuída ao jovem aprendiz por tudo aquilo que acontece na empresa. Também enfatizam a sobrecarga, o estresse e algumas formas de relacionamentos estabelecidos envolvendo aprendizes e funcionários. A relação com a chefia é do que menos gostam no programa, afirmando que existe uma distância entre a chefia e os aprendizes, seja pelo pouco contato, seja por questões de estresse ou por falta de diálogo.

Foi revelado que há uma responsabilização dos aprendizes por tudo que acontece na empresa, sendo muitas vezes sobrecarregados pelo trabalho exigido. Outra reclamação observada é a de serem colocados em setores de que não gostam ou com cujo serviço não se identificam. Vale ressaltar que a empresa é que define o setor que o jovem estará vinculado, devendo levar em consideração o curso técnico que estão realizando. Nesse contexto, eles também apresentam como aspecto negativo a dificuldade em lidar com pessoas - seja funcionários, seja clientes. Esse aspecto fez-se presente nas falas dos aprendizes entrevistados, reiteradas vezes, ao longo da pesquisa. Eles tratavam a aprendizagem de lidar com as pessoas como um desafio e atribuíam importância ao ensino de como fazer isso.

\section{Relação com funcionários e chefe na empresa}

A maioria dos aprendizes expressou em suas falas o tema do bom relacionamento com os funcionários. Mencionaram como aspectos positivos a construção de amizades, a aprendizagem e influência dos funcionários nessa aprendizagem. Esse bom relacionamento é visto pelos aprendizes como um aspecto positivo e aparece nas entrevistas como um discurso da instituição que realiza o programa acerca de como se deve trabalhar, prezando-se pelo "clima" 
na organização, como podemos perceber na seguinte fala: "Porque eles nos ajudam a nos dedicarmos ao curso" (Sexo Feminino, 16 anos).

Quando se referem à aprendizagem, amizade e influência, eles relatam que não acontece com todos, mas apenas com alguns funcionários, os que aceitam ajudá-los, servindo como exemplo de como devem agir e trabalhar na empresa. Pequena parte dos aprendizes expressou em suas falas a presença de aspectos negativos no relacionamento com os funcionários e ressaltaram o tratamento diferenciado que estes lhes dedicam e a desvantagem que sofrem por terem menos experiência que os funcionários.

Embora nem todos percebam que há aspectos negativos nas relações com os funcionários, deu-se, neste artigo, esse destaque, porque põe em questão o que é dito por eles nos aspectos positivos, como a afirmativa do bom relacionamento e da amizade. Mas faz sentido, na medida em que as justificativas para o tratamento diferenciado decorrem da ameaça em potencial que são os aprendizes para alguns funcionários. Segundo os relatos dos participantes da pesquisa, alguns funcionários não gostam de responder às perguntas feitas por eles. A explicação reside no receio que os funcionários mais antigos sentem em passar seus conhecimentos para os novatos e, em uma situação posterior de concorrência, de perder o emprego para os aprendizes.

Os aprendizes também expressaram em suas falas o tema do bom relacionamento com a chefia, salientando alguns fatores como a ajuda que recebem e a amizade que construíram. A maioria dos aprendizes entrevistados disse que só o fato de ter um bom relacionamento com o chefe já é um aspecto positivo. Esses aspectos seriam proveitosos para o crescimento dentro da empresa, um aliado da prática. Alguns, porém, afirmaram não ter tanto contato com o chefe, por isso não apontaram nenhum fator. Apesar de nem todos os aprendizes apresentarem aspectos negativos no relacionamento com os chefes, alguns reclamaram do estresse, da falta de tempo e de contato com dos chefes com eles. Embora nem todos identifiquem nisso aspectos negativos, a falta de diálogo e de tempo dos chefes para ensinar é apontada como elemento imprescindível no aprendizado e na formação do aprendiz, uma vez que os chefes acumulam saber e experiência na empresa e no mercado e poderiam repassar conhecimentos considerados indispensáveis a quem está em processo de aprendizagem.

\section{Aplicabilidade dos cursos à prática}

A vivência na formação é experimentada pelo ensino e aprendizagem de comportamentos a serem desempenhados na empresa e ausência de conhecimentos teóricos sobre a prática na empresa. As falas remetiam a: porque ensinam conhecimentos de direito e cidadania, usados na empresa e fora dela, no cotidiano; porque se aprende a lidar com os problemas do dia a dia, por exemplo, a aplicabilidade do que se aprende na instituição formadora; porque se 
aprende a se comportar na empresa; e porque se articulam prática e teoria. Em contrapartida, os que apontam insatisfação com o programa afirmam que a formação não ministra conhecimentos utilizados na empresa, mas que ela possui serviços que não são passados nas aulas teóricas.

\section{Experiência na formação}

Os entrevistados apontam a prática na empresa como um ponto a ser melhorado no curso oferecido pela instituição formadora no sentido de fornecer mais informações a respeito dela, isto é, cursos mais dinâmicos, conhecimentos relativos à prática, realização da capacitação durante a semana, renovação dos módulos, aumento do número dos capacitadores, módulos sobre inglês, mais rigor na hora da seleção dos aprendizes e exigência de mais atividades para fazer.

As sugestões apontadas pelos aprendizes estão em torno de questões do próprio currículo oferecido pela instituição: a renovação dos materiais utilizados por eles e a inserção do inglês no curso. Isso pode ser exemplificado nas seguintes falas: "Ensinar mais à gente como trabalhar, porque, se a gente pede aos funcionários, eles colocam dificuldade" (Sexo masculino, 17 anos), e na de um segundo aprendiz: "Focar mais o atendimento ao cliente" (Sexo masculino, 16 anos).

\section{DISCUSSÃO}

Os aprendizes entrevistados são, em sua maioria, do sexo feminino e se identificam como brancos. Como observa Segnini (2000), pesquisas nacionais já apontam que os índices de escolaridade das mulheres, a partir do oitavo ano de estudo, superam a escolaridade masculina, sendo um dos aspectos da conquista social das mulheres em busca de oportunidades equivalentes às dos homens. Esse aspecto chama a atenção, pois pesquisas organizadas por Alberto, Santos, Leite, Lima \& Wanderley (2011), na cidade de João Pessoa, mostram que, quando trabalham, as meninas apresentam baixa escolaridade; e que, quando só estudam, saem na frente dos meninos nesse quesito.

O fato de os dados sobre etnia revelar, nessa pesquisa, maioria branca coaduna-se com os dados da PNAD (2011) tanto no nível nacional como também quando se fala no estado da Paraíba. Há um aumento do acesso à escola ao longo dos anos, porém esse acesso e tempo de permanência ainda encontram-se bem discrepantes quando comparamos a cor de quem acessa. Na Paraíba, levando em conta pessoas com 15 ou mais anos, as pessoas brancas têm em média 7,2 anos de estudo, já as negras têm em média 5,0 anos de estudo, e as pardas têm 5,3 anos de estudo (PNAD, 2011).

Fazendo uma comparação entre os quesitos escolaridade, etnia e gênero, vê-se que o que foi encontrado na presente pesquisa condiz com o que é 
encontrado na literatura e nos dados nacionais, pois essa instituição tem como maioria aprendizes brancos, escolhidos, em maior número, através das notas na escola. E essa maioria é composta por aprendizes do sexo feminino, que, segundo a literatura (PNAD, 2011; Segnini, 2000), é a população com as melhores notas, cujo percentual de ocupação aumenta a cada ano, apesar de ainda não ser sua maioria no mercado de trabalho.

Da vivência desses jovens podemos elencar, segundo os dados coletados na presente pesquisa, a necessidade financeira $e$, consequentemente, de trabalho, ou seja, é o jovem pobre que necessita da renda do trabalho para si e para a família e da formação, para que, assim, possa minimamente garantir sua inserção no mercado de trabalho e adquirir condições de nele competir, seguida pela atividade profissional e de estudo. Prossegue, porém, a tônica histórica do jovem pobre que necessita das políticas de trabalho para que tenha alguma chance de se inserir no mercado de trabalho. Encontrando pela frente um estado voltado para o papel de mantenedor da hegemonia do capital, afeito ao neoliberalismo e disposto a gastar o mínimo com o trabalhador. mas por outro lado os dados revelam também a necessidade das políticas públicas para garantir os direitos sociais do cidadão, especificamente de uma política pública de formação profissional para esse jovem.

Vale salientar que, no processo de seleção para o programa de aprendizagem nessa instituição, um dos critérios são as notas escolares dos aprendizes encaminhadas por uma Instituição de Ensino Filantrópica mantida por uma instituição bancária. A inserção no PJA não foi demanda dos jovens, mas da instituição que faz a formação teórica, o que encontra semelhança com a pesquisa de Máximo (2012). A referida autora encontrou que, na percepção dos aprendizes assim como dos gerentes, a inserção no programa só acontece por força da lei e da ação fiscal do órgão fiscalizador. Em ambos, a inserção não aparece como demanda do jovem, mas fruto de ações externas, quer do órgão fiscalizador ou da instituição da formação teórica.

Tanto nesta pesquisa como na de Máximo (2012), as explicações para esse aspecto parecem residir nos seguintes elementos, encontrados em ambas as pesquisas: que o Programa Jovem Aprendiz é uma política pública desconhecida por parte da sociedade; que a forma de acesso é excludente, só alguns segmentos jovens conseguem acessar; que a maioria das empresas não aceita o programa, mas são obrigadas a receber o jovem. Questionar sua eficiência demandaria um estudo mais aprofundado, mas o que tem é que é uma política que fica aquém em relação à formação oferecida, não consegue inserir a todos, porém oportuniza mudanças nas vidas dos jovens que dela participam, possibilitando a construção de projetos de vida.

A seleção, feita pela instituição que faz a formação teórica a partir da escolha dos estudantes de uma escola, possibilitou que os jovens participantes percebessem e tomassem consciência da importância da escolaridade como um 
elemento fundamental que se articula com a formação profissional. Isso gerou um sentimento positivo de autoestima para esses selecionados, mas também um peso diante da responsabilidade que Ihes foi aferida por serem selecionados em detrimento de outros, o que promoveu uma adultização, ou seja, a assimilação de responsabilidades em detrimento da preparação para ela, que passa a ser sentida não como prêmio, mas como carga.

Os jovens participantes desta pesquisa internalizaram os discursos das pessoas que selecionaram e da escola que pregavam a importância, a sorte e o privilégio que tiveram. Eles assumem o discurso de que, embora não tenham buscado o programa, devem agarrar a oportunidade. Os jovens internalizaram e reproduziram a ideia de que aprenderiam e teriam uma experiência profissional, e isso se aliou às suas necessidades financeiras e de suas famílias e também ao discurso do mercado de que é necessário ter experiência para se conseguir um emprego. Essas mesmas categorias foram encontradas nos trabalhos de Macêdo (2006), Santos (2006) e Silva (2006) sobre O Programa Jovem Aprendiz, nos quais a experiência, a necessidade financeira e a aprendizagem foram fatores primordiais para a inserção o PJA.

A forma como os jovens percebem, interpretam a seleção para o programa e reagem emocionalmente a ele é mediada pelos significados que lhes são atribuídos pela sociedade (Toassa \& Souza, 2010). Nesse caso, a sociedade é representada pela própria instituição que seleciona e faz a formação teórica, pelo corpo da escola, pelos colegas e chefes da empresa e pela família. Mas como a vivência é uma unidade dinâmica da consciência, ela também comporta características da consciência e faz uma inter-relação entre os aspectos cognitivos e afetivos (Vigotski, 1933-1934/2006), no caso, o conhecimento e o sentimento desenvolvido por esses jovens ao experimentarem a formação teórica, a prática na empresa, o que, por sua vez, influencia o desenvolvimento desses jovens que passam a se ver e se perceber diferentes, como pessoas adultas com responsabilidades e que não podem falhar.

As suas vivências no programa de aprendizagem é a tomada de conhecimento de três dimensões: para uns é ser trabalhador, para outros é ser estudante em formação e para outros ainda é ser possuidor de um direito - que também é visto como um dever. Reflete ainda uma vivência de tomada de consciência, uma percepção de si e a construção de uma identidade a partir da relação com outras pessoas. Essa vivência comporta elementos diversificados que dependem do nível de desenvolvimento, do contexto, da situação experimentada (Vigotski, 1933-1934/2006).

Nesta pesquisa não foi possível mostrar (pois, não era seu objetivo) de onde vem cada elemento e o seu peso. Mas é possível visualizar que aparecem indicadores como: a identidade de trabalhador pode ter a ver com a prática na empresa; a identidade de estudante pode ter a ver com a escola e a formação teórica (alguns percebem a formação teórica como um reforço de português e 
matemática); e que ter direito pode remeter a diversos elementos: de cidadania, da política pública como direito do cidadão e obrigação do Estado (Sposito \& Carrano, 2003), ou de submissão, já que, para alguns, esse direito é um dever, revelando um aprendiz submisso às regras da empresa ou o aprendiz como aquele que tem que fazer o que os superiores mandam. Percebe-se isso quando os aprendizes falam, por exemplo: "O direito é seguir todas as regras que forem postas para a gente" (Masculino, 16 anos).

A partir de suas vivências na instituição e na empresa, os jovens interpretam que a aprendizagem de técnicas bancárias é importante na formação profissional, pois pode possibilitar o domínio de algumas técnicas relacionadas a atividade de trabalho demandada. Porém, os serviços de atendimento não formam um profissional para trabalhar em banco, pois em qualquer empresa se aprende ou se faz isso. A relação com as técnicas e as pessoas que a elas se ligam (funcionários do banco que repassam o conhecimento e gerentes) geram um sentimento de domínio, de poder de acesso ao conhecimento. Os serviços de atendimentos geram um sentimento de alguém desimportante, de peso, de carga e de desafeto com as responsabilizações que sob eles recaem quando ocorre algum problema ou erro na empresa, ou ainda decorrentes de fatores de estresses nas relações com funcionários ou chefes. São mobilizadores da saúde mental desses jovens que, devido ao processo de desenvolvimento, podem ter diferentes implicações dependendo do nível de desenvolvimento, de consciência e dos recursos que têm para compreender o interno e o externo (para uns é de estressores, para outros é de aprendizagem para lidar com essas situações no trabalho). São períodos críticos que levam a uma nova estrutura de personalidade e que constroem dialeticamente uma nova consciência e uma nova forma de relação com o meio (Vygotsky, 1989; Vigotski, 2006)

Assim, trata-se de uma política pública para formar jovens para o mercado de trabalho ou enquadra-se na crítica de Frigotto (2008) de que o curso profissionalizante não provém exatamente de uma política de formação, mas que a educação profissional se ajusta às relações de produção capitalista. Afinal, suas referências sociais mostram que é necessário adotar determinados comportamentos para que consigam permanecer ou até mesmo inserirem-se no mercado, garantindo o mínimo necessário.

A partir dessa inserção, o mundo subjetivo desses jovens passa a ser construído (também) pela inserção no Programa Jovem Aprendiz e na empresa em que realizam a prática, ou seja, é configurado pela interação das diversas formas de experiências que constituem esses jovens (Vigotski, 1933-1934/ 2006). Esse processo vai ocorrendo de forma mediada (na relação com os demais funcionários e também com os colegas de curso), assumindo as peculiaridades da inter-relação entre diversas experiências. Assim, tal programa tem influência na formação desse sujeito $e$, pelo que se percebe, segue pelo caminho da submissão ao mercado de trabalho, ou melhor, às regras da 
empresa para se configurar como trabalhador, o que para eles garantirá experiência no currículo, a primeira experiência de trabalho, possibilidades no mercado de trabalho e um diferencial na hora de ser contratado. Na vivência, especificamente na dos aprendizes, as referências de experiência, aprendizagem na empresa, as relações com os colegas, com a chefia e o lidar com público, além da responsabilidade, entram como condições para competir e buscar trabalho. Para isso, ele precisa de elementos para a comunicação, contextualizando a sua busca e preocupação com a atividade profissional e apresentando o que precisa para se inserir.

De forma geral, os aprendizes interpretam que a formação que eles têm, através da prática na empresa, garantirá a sua inserção no mercado de trabalho. Os dados conduzem à reflexão de que, para os aprendizes, há uma garantia da inserção de todos no mercado de trabalho, mas que essa inserção também dependerá deles, pois cabe a cada um adotar determinados comportamentos, aprendendo a ser um funcionário desejado pela empresa. Essas são exigências do mercado de trabalho e que, no decorrer da pesquisa, aparecem nas vivências dos aprendizes como condição de permanência no emprego e até de indicação para um futuro emprego. Em toda a pesquisa, percebe-se a ênfase que eles dão à prática na empresa, sendo a formação oferecida pela instituição deixada em segundo plano em suas falas e até criticada por eles. Se a prática na empresa deve estar ligada à teoria, reconhece-se que esta tem uma grande importância e deve ser revista pela instituição formadora de forma a contemplar a prática oferecida pelas empresas e as necessidades dos aprendizes.

Segnini (2000) analisa a relação trabalho e escolaridade e assegura que há contradições nessa relação. Afirma que a qualificação para o trabalho é uma relação social que envolve classes, gêneros, etnia, entres outros, e que vai muito além da escolarização e profissionalização, estabelecendo-se no interior dos processos produtivos de uma sociedade regida por valores, marcada por preconceitos e desigualdades. Sendo assim, a escolarização e a formação profissional são necessárias, porém insuficientes para a garantia de emprego. Esse é um assunto que também é tratado por Frigotto (2008) quando afirma que há falta e sobra de profissionais qualificados, denunciando a produção do trabalhador flexível e a formação tecnicista dada à classe dos trabalhadores.

Mais uma vez reforça-se a ideia de que o trabalho vem como uma via inevitável para os jovens, principalmente quando se trata da classe baixa, como mostraram Raupp e Milnitsky-Sapiro (2005), Sposito e Corrochano (2005), dentre outros. Assim, como foi discutido ao longo do texto, as vivências desse grupo de jovens nessa experiência de formação profissional, o Programa Jovem Aprendiz, coadunam-se com o que os autores mostraram, reafirmando que, no Brasil, as políticas públicas para a juventude têm no jovem pobre (Macêdo, 2006; Sposito \& Carrano, 2003) e no trabalho seu foco principal (Soares, 2009; Silva, 2006; Santos, 2006; Dias, 2006; Sposito \& Corrochano, 2005; Segnini, 
2000). A formação no Programa Jovem Aprendiz, na referida instituição, volta-se para a aquisição de elementos para inserção no mercado e não para aquisição de conhecimentos humanísticos (Macedo, 2012), volta-se para a aquisição de conhecimentos tecnicistas e aligeirados (Frigoto, 2008). As vivências desses jovens revelam aquilo que a sociedade prega: a aquisição de ferramentas e símbolos para competir no mercado. A dita experiência inscrita na cartilha, avalizada por uma instituição com fé de ofício, tem como foco a aprendizagem de como se comportar. Assim, a vivência é de preparação para que possam se inserir nas dimensões da vida social (Novaes, 2007) e para que adquiram as competências que se enquadrem na lógica do empregado produtivo, adaptável, que produza em tempo mínimo, e que sua mercadoria tenha aceitação imediata (Frigotto, 2008).

\section{CONSIDERAÇÕES FINAIS}

A pesquisa mostra que há indicadores que permitem compreender 0 Projeto de Jovem Aprendiz, pelos menos para esse grupo, como criador de oportunidades. Todavia cria paradoxos, pois, uma vez que não foi demandado pelos jovens, ao mesmo tempo em que cria oportunidades gera também sofrimentos, porque adultiza, cria responsabilidades que são sentidas como peso, reproduzindo assim uma ideologia de socialização de jovens pobres via trabalho.

Percebe-se, a partir deste estudo, que esses jovens foram levados a participar do programa, já que a instituição em que estudavam tinha essa parceria com a que oferece o curso. De certa forma, esses jovens "compram" a ideia de que tal oportunidade não poderia ser perdida e resolvem ingressar no programa, o que para eles proporcionou vivências de formação, mas também de adultização, aprendizagem de comportamento e responsabilização.

De certo modo para esses participantes a tônica do capitalismo foi alcançada, triunfou: de formar para o mercado. Mercado que demanda um trabalhador com uma formação essencialmente voltada para a prática, mas sobretudo submisso que se comporte essencialmente de acordo com os ditames da obediência e do cumprimento de regras.

Esses jovens vivenciam a prática na empresa como um ponto de destaque, aprendendo a se comportar, a se relacionar, a cumprir regras e a fazer o que mandam, destacando a prática na empresa em detrimento da formação, que avaliam como não sendo suficiente para as demandas da função na instituição bancária. Assim, enquanto política pública, o programa treina para a empresa, mas não forma teórica nem humanisticamente. 


\section{REFERÊNCIAS}

Alberto, M. F. P., Santos, D. P., Leite, F. M., Lima, J. W., \& Wanderley, J. C. V. (2011). O trabalho infantil doméstico e o processo de escolarização. Psicologia \& Sociedade, 23(2), 293-302. doi: 10.1590/S010271822011000200010

Amazarray, M. R.; Thomé, L. D., Souza, A.P.L., Poletto, M., \& Koller, S. H. (2009). Aprendiz versus trabalhador: Adolescentes em processo de aprendizagem. Psicologia: Teoria e Pesquisa, 25(3), 329-338. doi: 10.1590/S0102-37722009000300006

Bardin, L. (2007). Análise de conteúdo. Lisboa: Portugal: Edições 70.

Dias, R. S. (2006). O Impacto da formação desenvolvida pela parceria ONG Pia Sociedade com o Banco do Brasil na vida dos adolescentes do Programa de Aprendizagem- JP/PB. (Trabalho de Conclusão de Curso) Programa de PósGraduação em Serviço Social, Universidade Federal da Paraíba, João Pessoa, PB.

Frigotto, G. (2008). Educação profissional e capitalismo dependente: o enigma da falta e sobra de profissionais qualificados. Trabalho, Educação e Saúde, 5(3), 521-536. doi: 10.1590/S1981-77462007000300011

Macêdo, O. J. V. (2006). O sentido da formação para o trabalho e as expectativas em relação ao futuro por parte dos adolescentes aprendizes. (Dissertação) Programa de Pós-Graduação em Psicologia Social, Universidade Federal da Paraíba, João Pessoa-PB.

Macêdo, O. J. V. \& Alberto, M. F. P. (2012). O sentido da formação profissional no contexto da aprendizagem. Estudos de psicologia (Natal), 17(2), 223232. doi: 10.1590/S0100-55022008000300010

Ministério do Trabalho e Emprego (2006). Manual da aprendizagem: O que é que preciso saber para contratar o jovem aprendiz. Brasília: MTE, SIT, SPPE.

Máximo, T. A. C. O. (2012). Significado da formação e inserção profissional para gestores e aprendizes egressos do programa jovem aprendiz. (Tese de Doutorado) Programa de Pós-Graduação em Psicologia Social, Universidade Federal da Paraíba, João Pessoa, PB.

Novaes, R. (2007). Juventude e Sociedade: jogos de espelhos. Sentimentos, percepções e demandas por direitos e políticas públicas. Revista Sociologia Especial - Ciência e Vida, 1(2), 1-10.

PNAD (2011). Pesquisa Nacional por Amostra de Domicilio: síntese de indicadores. Instituto Brasileiro de Geografia e Estatística - IBGE.

Pochmann, M. (2000). A batalha do primeiro emprego. São Paulo: Publisher Brasil. 
Raupp, L. \& Milnitsky-Sapiro, C. (2005). Reflexões sobre concepções e práticas contemporâneas das políticas públicas para adolescentes: o caso da drogadição. Saúde e Sociedade, 14(2), 60-68. doi: doi.org/10.1590/S010412902005000200007

Rocha, S. (2008). A inserção dos jovens no mercado de trabalho. Caderno $C R H$, 21(54), 533-550. doi: 10.1590/S0103-49792008000300009

Santos, D. P. (2006). Relatório de Estágio em Psicologia Social na Delegacia Regional do Trabalho. João Pessoa: Universidade Federal da Paraíba.

Segnini, L. R. P. (2000). Educação e trabalho: uma relação tão necessária quanto insuficiente. São Paulo em Perspectiva, 14(2), 72-81. doi: 10.1590/S010288392000000200011

Silva, R. M. P. (2006). Programa adolescente aprendiz: Mecanismos Efetivos de Inserção dos Jovens no Mercado de Trabalho? (Trabalho de Conclusão de Curso) Programa de Pós-Graduação em Serviço Social, Universidade Federal da Paraíba, João Pessoa, PB.

Soares, O. J. (2009). Juventude e trabalho: notas e reflexões sobre a formação profissional mediada pela "Lei do Aprendiz" (Lei 10.097/00). Trabalho necessário, 7(8), 1-16.

Sposito, M. P. \& Carrano, P. C. R. (2003). Juventude e políticas públicas no Brasil. Revista Brasileira de Educação, (24), 16-39. doi: 10.1590/S141324782003000300003

Sposito, M. P. \& Corrochano, M. C. (2005) A face oculta da transferência de renda para jovens no Brasil. Tempo social, 17(2), 141-172. doi: 10.1590/S0103-20702005000200007

Souza. J. S. (2009). Trabalho, juventude e qualificação profissional: A pedagogia da hegemonia das políticas de inclusão de jovens no Brasil. In I Seminário Nacional Sociologia e Política UFPR "Sociedade e Política em Tempos de Incerteza". Sociologia e Política. Recuperado de www.humanas.ufpr.br/site/evento

Teixeira, E. S. (2003). A questão da periodização do desenvolvimento psicológico em Wallon e em Vigotski: alguns aspectos de duas teorias. Educação e Pesquisa, 29(2), 235-248. doi: 10.1590/S1517-97022003000200003

Toassa, G. (2009). Emoções e vivências em Vigotski: investigação para uma perspectiva histórico-cultural. (Tese de Doutorado) Programa de PósGraduação em Psicologia. Universidade de São Paulo.

Toassa, G. \& Souza, M. P. R. (2010). As vivências: questões de tradução, sentidos e fontes epistemológicas no legado de Vigotski. Psicologia USP [online], 21(4), 757-779. doi: 10.1590/S0103-65642010000400007

Thomé, L. D., Telmo, A. Q. \& Koller, S. H. (2010). Inserção laboral juvenil: contexto e opinião sobre definições de trabalho. Paidéia, 20(46), 175-185. doi: $10.1590 /$ S0103-863X2010000200005 
Vigotski, L. S. (1933-1934/2006). La crisis de los siete años. In: L. S., Vigotski (Org), Obras Escogidas. Tomo IV (pp. 377-386). Madrid: Espanha: Visor y A. Machado Libros.

Vygotsky, L. S. (1989). Pensamento e linguagem. (2a ed.) São Paulo: Martins Fontes.

Yamamoto, O. H., \& Oliveira, I. F. (2010). Política social e psicologia: Uma trajetória de 25 anos. Psicologia: Teoria e Pesquisa, 26 (1), 9-24. doi: 10.1590/S0102-37722010000500002

Sobre os autores

Manuella Castelo Branco Pessoa é psicóloga, mestre em Psicologia e doutoranda em Psicologia Social vinculada ao Programa de Pós-Graduação em Psicologia Social da Universidade Federal da Paraíba, bolsista da CAPES, membro do Núcleo de Pesquisa e Estudos sobre Infância e Adolescência (NUPEDIA). E-mail: manucastelobranco2@gmail.com

Maria de Fátima Pereira Alberto é Professora Adjunta do Departamento de Psicologia e do Programa de Pós-Graduação em Psicologia Social da Universidade Federal da Paraíba. Doutora em Sociologia pela Universidade Federal de Pernambuco. Coordenadora do Núcleo Pesquisa e Estudos sobre o Desenvolvimento da Infância e Adolescência (NUPEDIA) da UFPB e pesquisadora do CNPq. E-mail: jfalberto@uol.com.br.

Recebido em: 18/07/2014

Revisado em: 23/10/2014

Aceito em: 04/02/2015 